\title{
Omental infarction: An uncommon aetiology for acute abdomen
}

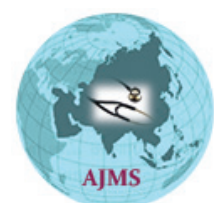

Dear Editor,

Acute abdomen can be life threatening and is considered as a surgical emergency. Some of the common causes are acute appendicitis, perforated peptic ulcer with acute peritonitis, acute pancreatitis, ruptured aortic aneurysm, acute mesenteric ischemia, intestinal obstruction, ruptured ectopic pregnancy and pelvic inflammatory disease. ${ }^{1}$ Omental infarction (OI) is an uncommon cause of acute abdomen; and its presentation can mimic other aetiologies. Primary or idiopathic omental torsion is a rare event which occurs without any coexisting condition; while secondary $\mathrm{OI}$ is seen in association with abdominal pathologies like inguinal hernia, tumours, cysts, pelvic inflammatory disease or adhesions from previous intra-abdominal surgery. ${ }^{2}$ About $0.1 \%$ of all laparotomies performed for acute abdomen was due to greater OI. ${ }^{3}$ The superfluous nature of omentum, its vascularity, increased intra-abdominal pressure and increased peristalisis following over eating are some of the pathophysiological mechanisms behind OI. Obesity, adult age (40-50 years), male gender, exertion, local trauma and sudden change of body posture are some of the precipitating factors. ${ }^{4}$ The right side of the omentum is more commonly involved because of its greater length and mobility, which allows it to tort along the long axis. As a result, these patients present with right sided abdominal pain. ${ }^{5}$ Crofoot observed that $90 \%$ of all OI were right sided.

The case being reported is of a 24 year old male, who presented to the Emergency department with complaints of colicky abdominal pain over the right iliac region with no radiation, for the past 4 days. He was conscious, oriented, moderately build and nourished, with stable vitals. He was not icteric. His abdominal examination revealed tenderness in the right hypochondrium and right iliac fossa on palpation, which was associated with guarding. Rebound tenderness was present over the right iliac region. Bowel sounds were heard normally. His complete blood count showed mildly elevated total counts of 12,500/ cmm (4000-11000) with differential counts as N80 L20. His renal and liver functions, electrolytes, amylase, PT/INR and urine microscopy were normal. Abdominal ultrasound showed a well-defined oval area of
Access this article online

Website:

http://nepjol.info/index.php/AJMS

DOI: 10.3126/ajms.v8i1.15979

E-ISSN: 2091-0576

P-ISSN: 2467-9100

hyperechogenicity in the right hypochondrium measuring around $7 \mathrm{~cm}$ and contrast CT abdomen revealed focal area of fat stranding, thereby confirming the diagnosis of omental infarction (Figure 1). He was managed conservatively with injection cefotaxime and analgesics; and was discharged asymptomatic on day 5 of admission.

$\mathrm{OI}$ is a rare scenario, especially in its primary form. Because of its non-specific clinical presentation, it can mimic other surgical causes of acute abdomen. Abdominal ultrasound and computerized tomography can aid in its diagnosis. The condition can be managed conservatively; with surgical intervention i.e. omentectomy being reserved for complications like omental abscess, intestinal obstruction or adhesions, failure of conservative management, or in those cases where diagnosis remains as query.A laparascopic approach is preferred. Surgery can hastens the resolution of symptoms, thus enabling faster patient discharge. Moreover, removing the devitalised omentum can reduce the incidence of secondary peritoneal abscess. ${ }^{7,8}$

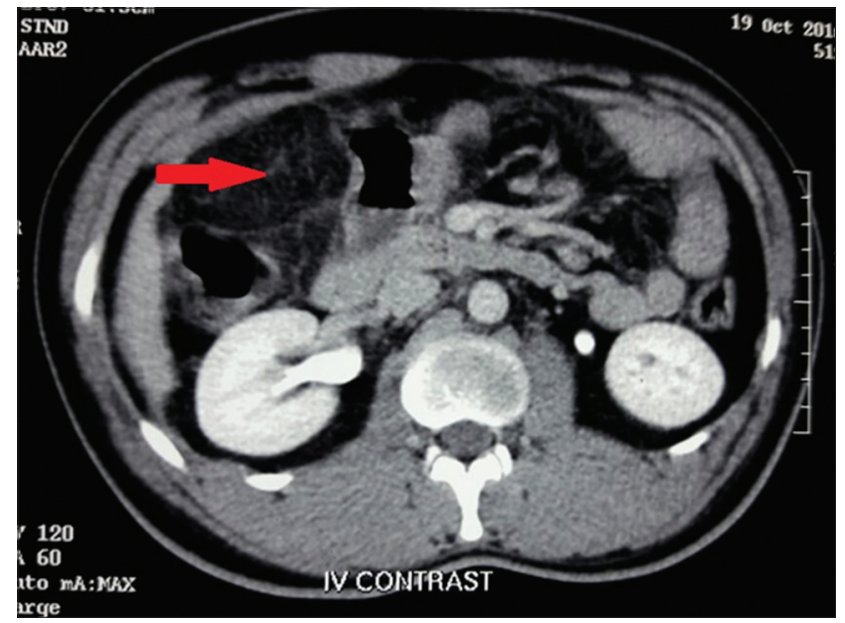

Figure 1: Omental infarction 
OI should be considered among the list of differential diagnosis for acute abdomen, thereby withholding surgical management unless indicated.

\section{Chinganthara Cleetus Suresh ${ }^{1}$, Robin George Manappallil ${ }^{2}$, Adarsh Chand ${ }^{3}$, Jishnu Jayaraj ${ }^{4}$}

${ }^{1}$ Senior Consultant and Head, ${ }^{3}$ Resident, Department of General Surgery, ${ }^{2}$ Consultant-Physician, ${ }^{4}$ Resident, Department of Internal Medicine, Baby Memorial Hospital, Calicut, Kerala, India

Address for correspondence: Dr. Robin George Manappallil, Consultant - Physician, Department of Internal Medicine, Baby Memorial Hospital, Calicut, Kerala - 673 004, India. E-mail: drrobingeorgempl@gmail.com, Phone: 0091-8547753396

\section{REFERENCES}

1. Ford MJ, Mac Gilchrist A and Parks RW. The gastrointestinal system. In: Douglas, Nicol, Robertson eds. Macleod's Clinical
Examination. $12^{\text {th }}$ ed. China: Elsevier; 2009: 209-211.

2. Concannon ES, Hogan AM, Ryan RS, Khan W and Barry K. Primary omental infarction: a rare cause of acute abdominal pain. Clinical and Experimental Medical Sciences 2013; 1(5-8):233-240.

3. Lardies JM, Abente FC, Napolitano A, Sarotto $L$ and Ferraina $P$. Primary segmental infarction of the greater omentum: a rare cause of RLQ syndrome: laparoscopic resection. Surg Laparosc Endosc Percutan Tech 2001; 11(1):60-62.

4. Jeganathan R, Epanomeritakis $\mathrm{E}$ and Diamond T. Primary torsion of the omentum. Ulster Med J 2002; 71:76-77.

5. Lutolf ME, Steinauer-Gebauer AM and Yee J. Torsion of the greater omentum with infarction: the vascular pedicle sign, Clinical Radiology 2001; 56(12):999-1002.

6. Crofoot DD. Spontaneous segmental infarction of the greater omentum. The American Journal of Surgery 1980; 139(2):262-264.

7. Danikas D, Theodorou S, Espinel J, Schneider C. Laparoscopic treatment of two patients with omental infarction mimicking acute appendicitis. JSLS 2001; 5(1):73-75.

8. Costi R, Cecchini S, Randone B, Violi V, Roncoroni L, Sarli L. Laparoscopic diagnosis and treatment of primary torsion of the greater omentum. Surg Laparosc Endosc Percutan Tech 2008; 18 (1):102-105.

Authors Contribution:

CCS- Critical revision of manuscript and treating surgeon; RGM-Concept and design of case report, reviewed the literature, manuscript preparation, and treating physician; AC- Surgery resident incharge; JJ- Medicine resident incharge.

Source of Support: Nil, Conflict of Interest: None declared. 